\title{
Os Eventos Esportivos e a Indústria do Esporte no Brasil
}

Sports Events and the Sports Industry in Brazil

Los eventos deportivos y la industria del deporte en Brasil

Gisele Kede Flor Ocampo' Alexsander Gomes de Azevedo ${ }^{2}$ Alexandre Lima de Araújo Ribeiro ${ }^{3}$ Paulo Henrique Azevêdo ${ }^{4}$

\section{Resumo}

Introdução: Uma vez que os eventos esportivos são capazes de transmitirem a emoção, superação, confraternização, respeito, disciplina e, principalmente, a felicidade que envolve o esporte, estes tornam-se um instrumento favorável ao crescimento e valorização do esporte. Objetivo: Analisar o crescimento dos eventos esportivos das modalidades Olímpicas no Brasil entre os anos de 2008 a 2016. Métodos: Esta foi uma pesquisa bibliográfica com análise documental a partir do levantamento de referências teóricas já analisadas e publicadas. Foram pesquisados e analisados registros de órgãos responsáveis pelo esporte como confederações e entidades esportivas. Resultados: O Brasil realizou dentro da categoria Olímpica, de 2008 a 2016 mais de 7.000 eventos em 39 modalidades esportivas. Dentre estes, $63 \%$ foram eventos estaduais e $18 \%$ nacionais. A região sudeste foi a maior realizadora de eventos esportivos, entre 2008 e 2016, na categoria olímpica desenvolvendo mais de 3.000 eventos. Só no ano de 2014 foram realizados 1.600 eventos sendo 64\% estaduais. Conclusão: De 2008 a 2016 houve um crescimento na realização de eventos esportivos no país em diversas modalidades esportivas. Sendo assim, a aplicação do marketing esportivo na Indústria do Esporte deve continuar em crescimento na busca de mais interação da sociedade com o esporte por meio dos eventos esportivos.

Palavras - chave: Esportes. Atividades de lazer. Marketing Esportivo.

\begin{abstract}
Introduction: Since sporting events are able to transmit the emotion, overcoming, fraternization, respect, discipline and, above all, the happiness that surrounds the sport, these become an instrument favorable to the growth and valorization of the sport. Objective: Analyze the growth of Olympic sports events in Brazil between 2008 and 2016, identifying the great market that sporting events offer. Methodology: This was a bibliographical research made from the survey of theoretical references already analyzed, and published. Records of bodies responsible for sport such as confederations and sports entities were searched and analyzed. Results: In the Olympic category, from 2008 to 2016, Brazil performed more than 7,000 events in 39 sports. Among these, 63\% were state and $18 \%$ national events. The southeastern region was the largest sports event organizer, between 2008 and 2016, in the Olympic category developing more than 3.000 events. In the year 2014 alone, 1.600 events were held, $64 \%$ of which were state. Conclusion: The sport acquired a high commercial value, being seen and perceived as a profitable product, reaching the status of Industry. Thus, although sporting events are presented in different modalities and in a satisfactory number, there is still a need for
\end{abstract}

1. Mestre em Educação Física - Universidade de Brasília - UnB, Brasília, Distrito Federal (gikede@gmail.com). 2. Autor de correspondência: professor Associado III da Faculdade de Educação Física - FEF/UnB - Universidade de Brasília - UnB, Brasília, Distrito Federal (pha@gesporte.net). 
greater application of sports marketing in the sports industry in the search for more interaction between society and sport.

Keywords: Sports. Leisure activities. Sports Marketing.

\section{Resumen}

Introducción: Una vez que los eventos deportivos son capaces de transmitir la emoción, superación, confraternización, respeto, disciplina y, principalmente, la felicidad que envuelve el deporte, estos se convierten en un instrumento favorable al crecimiento y valorización del deporte. Objetivo: Analizar el crecimiento de los eventos deportivos de las modalidades Olímpicas en Brasil entre los años 2008 a 2016. Métodos: Esta fue una investigación bibliográfica con análisis documental a partir del levantamiento de referencias teóricas ya analizadas y publicadas. Se investigaron y analizaron registros de órganos responsables del deporte como confederaciones y entidades deportivas. Resultados: Brasil realizó dentro de la categoría Olímpica, de 2008 a 2016 más de 7.000 eventos en 39 modalidades deportivas. Entre estos $63 \%$ fueron eventos estaduales y $18 \%$ nacionales. La región sudeste fue la mayor realizadora de eventos deportivos, entre 2008 y 2016, en la categoría olímpica desarrollando más de 3.000 eventos. Sólo en el año 2014 se realizaron 1.600 eventos siendo 64\% estatales. Conclusión: De 2008 a 2016 hubo un crecimiento en la realización de eventos deportivos en el país en diversas modalidades deportivas. Siendo así, la aplicación del marketing deportivo en la industria del deporte debe continuar en crecimiento en la búsqueda de más interacción de la sociedad con el deporte a través de los eventos deportivos.

Palabras clave: Deportes. Actividades de ócio. Marketing deportivo.

\section{INTRODUÇÃO}

O futebol é considerado uma manifestação cultural, que no Brasil ocorreu de forma abrangente, e conseguiu transformar esse esporte em uma característica do povo brasileiro. Mas além do futebol, o Esporte é definido como diversão ou uma atividade física, que faz as pessoas se envolverem por prazer, gerando emoções e sensações dentro do consumo esportivo'. Por isso, há uma intensa busca pela excelência no segmento, pois o consumidor está cada vez mais interessado em novidades e possibilidades de conhecer novas modalidades esportivas. E, independente da atividade esportiva ser amadora ou profissional, faz-se necessário a profissionalização ${ }^{2}$.

\section{O Marketing é um processo} social por meio dos quais pessoas e grupos de pessoas obtêm aquilo de que necessitam e o que desejam com a criação, oferta e livre negociação de produtos e serviços de valor com outros ${ }^{3}$. Desta forma, as inovações tecnológicas, como em outros períodos da evolução da nossa civilização, influenciaram fortemente o mundo do Marketing.

O marketing esportivo é um derivado do marketing aplicado ao segmento de esportes, e, assim sendo, engloba uma série de elementos que compõem o tradicional mix de marketing - produto, preço, promoção e 
praça ${ }^{4}$. Portanto, o Marketing Esportivo pode ser definido como o conjunto das técnicas que têm como objetivo tornar o esporte conhecido e de prática sistemática, adequando-o nos diversos fatores de desenvolvimento, às características, necessidades e anseios da população, procurando obter o máximo de benefícios, utilizando para o efeito, o mínimo de recursos ${ }^{5}$.

Segundo Morgan e Summers', existem duas grandiosas vertentes para a definição de Marketing Esportivo. A primeira associa o marketing esportivo à tomadas de decisões estratégicas, que as empresas utilizam o esporte como veículo para alcançar atenção, o desenvolvimento uma marca ou imagem corporativa, ou até mesmo, comunicar benefícios específicos de um produto a um grupo alvo. Nessa perspectiva, as empresas objetivam uma ótima divulgação de suas marcas ao associá-las a bons conceitos enraizados no esporte, como os de sucesso e de vitória, além de, através de tal correlação com esporte, chegarem com seus produtos ao consumidor de forma mais rápida e direta. As empresas utilizam o esporte como meio para divulgação de seus produtos, pois este possui alto grau de segmentação de mercado dentro de um dado universo social ${ }^{6}$.
A segunda vertente do Marketing Esportivo mostra que as estratégias de marketing são utilizadas para ajudar os órgãos esportivos a atingir suas metas e seus objetivos corporativos e a se comunicar com seus diversos públicos ${ }^{1}$. Assim, o esporte é encarado como um produto a ser idealizado, divulgado e comercializado, com a finalidade de se alcançar mercados interessados nesse produto. Portanto, o marketing esportivo seria a aplicação dos princípios de marketing a qualquer produto relacionado à indústria do esporte.

Além dessas duas perspectivas acerca da relação entre marketing e esporte, alguns acreditam que o marketing esportivo seria destinado, exclusivamente, para a venda de eventos esportivos $^{7}$, que são de grande importância para a sociedade, uma vez que envolvem a emoção, superação, confraternização, respeito, disciplina e, principalmente, a felicidade que o esporte proporciona aos indivíduos praticantes, ou não. Além disso, os eventos esportivos são capazes de envolver várias áreas do conhecimento como a Educação Física, Saúde, Política, Sociologia, Economia e Administração, dentre outras.

Sendo assim, como afirma Kotler $^{8}$, o marketing vai além de apenas conseguir vender um produto. Desta 
forma, o Marketing Esportivo pode trabalhar a favor do esporte na disseminação das suas diversas modalidades utilizando os eventos esportivos como ferramenta de entretenimento e lazer.

Diante deste cenário, esta pesquisa analisou o crescimento dos eventos esportivos das modalidades Olímpicas no Brasil entre os anos de 2008 a 2016.

\section{Breve história do Marketing Esportivo no Brasil}

Ao longo do século XX, a difusão de hábitos esportivos e a conformação de uma cultura de massa levaram à expansão do consumo de artefatos, equipamentos e serviços relacionados à prática esportiva, assim como transformaram os principais eventos esportivos em espetáculos altamente veiculados pela mídia?. Em consequência dos acontecimentos descritos, o esporte tornou-se nas últimas décadas um dos veículos de comunicação mais utilizados pelo mundo empresarial para difundir produtos e consolidar marcas mundiais ${ }^{10}$. Indústria é um mercado que vende a consumidores produtos estreitamente relacionados ou semelhantes diferenciando-se de acordo com as suas necessidades, vontades e desejos. Define-se como indústria como um mercado no qual os produtos oferecidos aos compradores relacionamse a esporte, fitness, recreação ou lazer e podem incluir atividades, bens, serviços, pessoas, lugares ou ideias ". Pitts e Stotlar $(2002)^{11}$ citam ainda alguns exemplos dos tipos de produtos oferecidos pela indústria do esporte:

- Esportes oferecidos como produto de participação, como a participação em uma liga de basquete recreativo para mulheres;

- Esportes oferecidos como produto para espectadores, como um jogo de beisebol, futebol, UFC;

- Equipamentos e acessórios necessários para a prática de atividades esportivas e de fitness, como calçados específicos, joelheiras, tocas, raquetes, entre outros;

- Brindes promocionais usados para promover esportes, eventos esportivos ou atividades de fitness, como bonés, chaveiros com símbolos, toalhas, entre outros;

- Instalações necessárias para a prática do esporte;

- Serviços diversos, como encordoamento de raquetes, lavanderia, confecção de redes de várias modalidades, entre outros;

- Atividades recreativas, como camping, equitação, corridas de rua, ciclismo radical, entre outros;

- Administração e marketing completos para eventos esportivos, como corridas de rua, campeonatos de skate, voo livre, entre outros;

- Oferta de indivíduo para tratar de assuntos financeiros, legais, contratuais e promocionais de um atleta profissional;

- Ofertas de empresas de consultoria esportiva para ar suporte aos interessados nesse mercado; 
- Revistas sobre esportes específicos e outras atividades oferecidas por editoras.

Apesar desta vasta gama de produtos a serem oferecidos aos interessados no esporte pode-se afirmar que a indústria do esporte se diversificou ao longo do tempo, muito em função das exigências e necessidades da sociedade, influenciadas pelos acontecimentos históricos que marcaram a evolução do mundo. Para Pitts e
Stotlar $(2002)^{11}, \quad$ o profissional de marketing deve considerar constantemente o que afeta a indústria, afinal tal fato pode ser relevante na escolha de certo produto, podendo levar um segmento ou empresa ao sucesso ou a falência. A seguir os fatores que influenciam o crescimento da indústria do esporte seja no passado, presente ou futuro:

Quadro 1. Fatores que influenciam o crescimento da indústria do esporte - passado, presente e futuro.

\section{FATORES IMPORTANTES}

1. Aumento no número de novas e diferentes atividades esportivas, de fitness e recreativas.

2. Aumento na oferta desses esportes.

3. Aumento no número e tipos de revistas esportivas e revistas especializadas.

4. Aumento do tempo de lazer.

5. Aumento da exposição à mídia de massa.

6. A explosão do fitness na década de 70 .

7. Aumento do número e tipos de instalações, eventos e participacão.

8. Aumento na expansão dos bens e serviços relacionados ao esporte para variedade de segmentos de mercado.

9. Aumento no número e tipos de atividades esportivas, de fitness e recreativas em nível profissional.

10. A transição das instalações de único propósito para as instalações

de multiuso.

11. Aumento do esporte para a diversidade das populações.

12. Aumento de patrocínio e de fundos para o esporte por parte da comunidade empresarial em geral.

13. Aumento dos endossos.

14. Aumento da educação esportiva.

15. Aumento dos lucros.

\section{EXEMPLOS DAS MUDANCAS}

Caiaque de neve, ice surfing, bungee-jumping, windsurf, hang gliding e paralyzing.

Crescimento de oferta para a prática do vôlei e futebol americano.

Revistas de caça, vela, remo, mountain biking, ralis, esportes aquáticos, corrida, caminhada, camping.

As horas de folga são mais utilizadas para o lazer.

Grande influência da televisão na transmissão dos eventos esportivos.

Aumentou a consciência da população em geral quanto a condicionamento físico, bem-estar e saúde.

Aumento na construção de espaços que estimulam a atividade e prática esportiva.

Os valores sociais influenciam tal expansão, a estrutura familiar vem se modificando (homossexuais, mulheres no comando das famílias) e equipamentos para deficientes físicos.

Atividades que antes eram amadoras e que se

Tornaram profissionais: Jet ski, corridas de caminhões, de cachorros, barcos e o fisiculturismo entre outros.

Construção de espaços que serão utilizados por vários públicos, ou seja, várias modalidades esportivas e atividades culturais.

A legislação tem forçado o aumento de oportunidades em atividades esportivas, de fitness ou recreativas.

Observe um carro de corrida, várias empresas querem ver suas marcas neles e desejam que o público se lembre de seu nome.

Uma marca vinculada a um atleta famoso, time ou organização. Ex: Ronaldo com a NIKE.

Pode ser utilizada como um meio de promover e incentivar a participação no esporte e promover outros produtos esportivos.

O aumento nas vendas de tudo relacionado ao esporte incrementou o lucro global da indústria do esporte. 


\begin{tabular}{|l|l|}
\hline $\begin{array}{l}\text { 16. Aumento da tecnologia em bens, } \\
\text { serviços e treinamento relacionados ao } \\
\text { esporte. }\end{array}$ & $\begin{array}{l}\text { Influência da tecnologia nos equipamentos, instalações, } \\
\text { vestuário, calçados esportivos e programa de treinamentos. }\end{array}$ \\
\hline $\begin{array}{l}\text { 17.Destaque do esporte como produto de } \\
\text { consumo. }\end{array}$ & $\begin{array}{l}\text { As academias se tornaram quase um lar longe de casa. As } \\
\text { empresas agregam o consumo de outros produtos ao } \\
\text { esporte. }\end{array}$ \\
\hline $\begin{array}{l}\text { 18. Aumento do marketing e da orientação } \\
\text { da indústria do esporte para o marketing. }\end{array}$ & $\begin{array}{l}\text { Os esportes têm mudados suas regras para que eles se } \\
\text { tornem mais negociáveis. Regras do basquete por } \\
\text { exemplo. }\end{array}$ \\
\hline $\begin{array}{l}\text { 19. Aumento da competência na } \\
\text { administração do esporte. }\end{array}$ & $\begin{array}{l}\text { Crescente oferta de programas de estudos em nível de } \\
\text { graduação, mestrado e doutorado. }\end{array}$ \\
\hline 20. A globalização e a indústria do esporte. & $\begin{array}{l}\text { Quem imaginaria as copas do mundo nos EUA e África } \\
\text { do Sul? }\end{array}$ \\
\hline
\end{tabular}

Fonte: Pitts e Stotlar (2002) adaptado pelos autores.

Além destes fatores, Pitts, Fielding \& Miller $^{12}$ publicaram um estudo em que dividiu a indústria em segmentos com o foco nos produtos e compradores, ou seja, cada produto foi considerado de acordo com a sua função ou benefício ao consumidor, portanto três segmentos industriais foram identificados: o segmento da indústria da prática esportiva, o segmento da indústria de produção esportiva e $\mathrm{o}$ segmento da indústria da promoção esportiva.

A atividade do marketing esportivo, até o fim da década de 1960 e começo da década de 1970, estava voltada, prioritariamente, para os principais eventos do cenário esportivo mundial, como as Olimpíadas. Nessa época, empresas fabricantes de cigarro foram proibidas de vincular seus comerciais em televisões e rádios, em alguns governos da Europa, dos Estados Unidos e na Austrália. Com isso, essas empresas procuraram abrigo no esporte para conseguir expor os seus produtos a seus mercados ${ }^{1}$.

Na década de 1980 e início de 1990 diversas empresas como Parmalat, Unicor, Tintas Renner, General Motors, Lubrax, Umbro, Nike, General Motors, Bombril começaram efetivamente a vincular suas marcas a algumas modalidades esportivas. $\mathrm{O}$ futebol foi $\mathrm{O}$ carro chefe dessas iniciativas. Vê-se, portanto que boa parte dos investimentos desde então são feitos nos eventos esportivos.

Para muitos autores, a motivação que levou grandes empresas a investirem no esporte está proporcionalmente ligada ao espaço que a mídia em geral reservou para a divulgação dos eventos em virtude do sucesso obtido em grandes competições nacionais e internacionais e o retorno institucional e de vendas que eles traziam.

\section{MÉTODOS}

$$
\text { Esta foi uma pesquisa }
$$
documental realizada com base nos dados coletados pelo "Projeto 
Referências” desenvolvido pela Universidade Federal do Rio Grande do Sul - UFRGS/Ministério do Esporte ${ }^{13}$. O "Projeto Referências" se baseou em buscas on-line em sites de instituições responsáveis pelas modalidades esportivas e em sites de divulgação online dos eventos desenvolvidos nas diversas modalidades olímpicas entre 2008 e 2016. Foram pesquisados eventos esportivos organizados por entidades brasileiras, em nível internacional, nacional, regional, estadual e municipal. Foram consultadas as instituições: Ministério do Esporte Calendário Desportivo Nacional; Comitê Olímpico Internacional; Federações e Organizações Desportivas Internacionais; Confederações Nacionais; Federações Estaduais; Secretarias Estaduais e Municipais de Esporte. As informações dos eventos realizados entre os anos de 2008 e 2016 foram armazenadas em planilhas do Programa Microsoft Excel 97-2003.

\section{RESULTADOS}

O esporte Olímpico Brasileiro apresenta 39 modalidades no esporte de alto rendimento ${ }^{13}$. São elas: atletismo, badminton, basquetebol, boxe, canoagem slalon, canoagem velocidade, ciclismo BMX, ciclismo de estrada, ciclismo de pista, ciclismo mountain bike, esgrima, futebol, ginástica artística, ginástica de trampolim, ginástica rítmica, golfe, handebol, hipismo adestramento, hipismo CCE, hipismo salto, hóquei sobre grama, judô, levantamento de peso, luta greco-romana, luta estilo livre, nado sincronizado, natação, pentatlo moderno, polo aquático, remo, rúgbi de 7, saltos ornamentais, taekwondo, tênis, tênis de mesa, tiro esportivo, triatlo, vela, voleibol, voleibol de praia.

O Brasil realizou dentro da categoria Olímpica, de 2008 a 2016, 7.092 eventos $^{13}$. Sendo eles classificados como campeonatos, torneios, circuitos, copas, ligas e Jogos de todas as modalidades citadas, a nível mundial, estadual, continental, nacional e regional $^{13}$. Dentre estes mais de 63\% foram eventos estaduais e $18 \%$ nacionais, conforme o Gráfico 1.

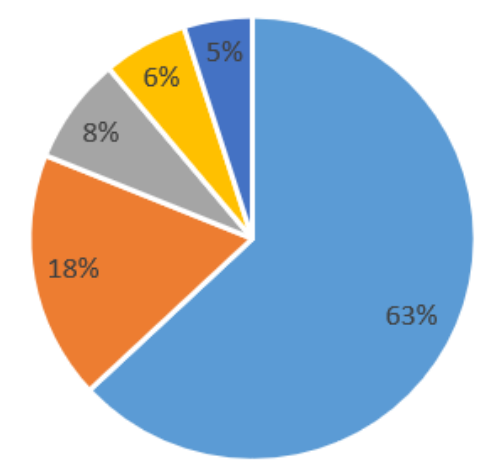

$$
\begin{aligned}
& \text { - Estadual }=\text { Nacional }=\text { Mundial } \\
& \text { " Regional }=\text { Continental }
\end{aligned}
$$

Gráfico 1- Nível dos eventos esportivos ocorridos entre os anos de 2008 e 2016 no Brasil. Fonte: Projeto Referências (2016). 
De 2008 a 2016 foram realizados mais de 3.000 eventos esportivos na categoria olímpica na região sudeste. Esta foi a região com mais eventos realizados (gráfico 2).

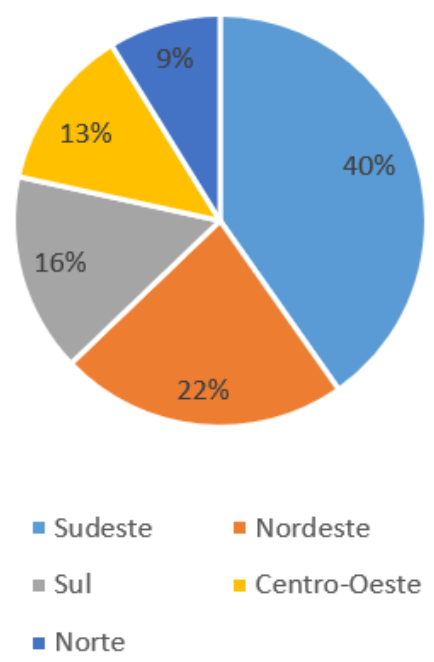

Gráfico 2 - Eventos esportivos ocorridos, entre 2008 e 2016, por região. Fonte: Projeto Referências (2016).

O ano de 2014 foi que mais desenvolveu eventos e nota-se que o número de eventos caiu posteriormente nos anos de 2015 e 2016, mas ainda mostrando um crescimento no número de eventos em relação aos anos anteriores a 2014 (Gráfico 3). No ano de 2014 então forma desenvolvidos mais de 1600 eventos sendo $64 \%$ estaduais (Gráfico 4).

\section{DISCUSSÃO}

Por meio do marketing esportivo o Brasil apresentou durante muitos anos um grande desenvolvimento do Futebol. Atualmente, pode-se verificar um grande crescimento em outras modalidades esportivas despertando o interesse das pessoas tanto na prática destas modalidades quanto no consumo de eventos esportivos. Inclusive os Jogos Olímpicos sediados no Brasil em 2016, trouxeram um olhar para o esporte provocando mais interesses em modalidades não tão conhecidas como badminton, canoagem, esgrima, levantamento de peso e rúgbi.

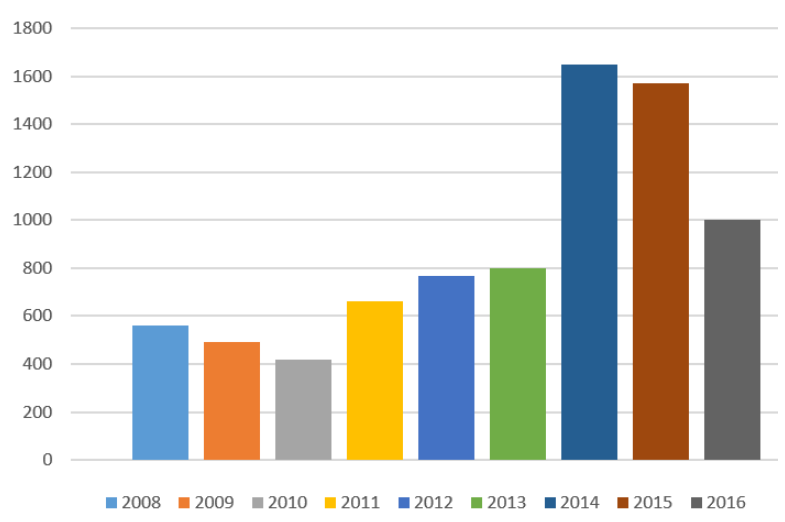

Gráfico 3 - Realização de eventos esportivos no Brasil, por ano. Fonte: Projeto Referências (2016).

O Brasil apresenta as conquistas da Copa do Mundo (1958, 1962, 1970, 1994 e 2002), Copa das Confederações (1997, 2005, 2009 e 2013), e pelos últimos eventos sediados no Brasil (Copa das Confederações, Copa do Mundo, Jogos Olímpicos e Paraolímpicos), que trouxeram muita euforia para os brasileiros. Por isso, acredita-se que o Brasil possa investir mais em eventos menores e não apenas em megaeventos que visam lucro e crescimento de uma indústria que não beneficia diretamente os amantes do 
esporte e sim a lucratividade de grandes nomes e grandes empresas.

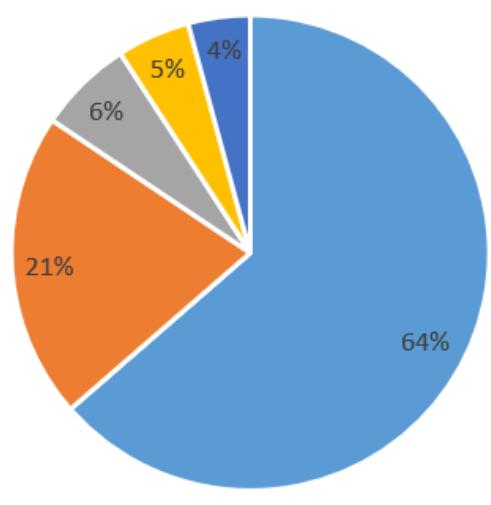

- Estadual = Nacional = Mundial

- Regional - Continental

Gráfico 4 - Nível de eventos esportivos ocorridos no Brasil no a no de 2014. Fonte: Projeto Referências (2016).

O esporte de competição, que foi se profissionalizando ao longo do século passado, foi gerando novas formas de consumo $^{14}$ e apresentando grande crescimento dos megaeventos esportivos. Mas ao mesmo tempo, o esporte apresentou crescimento também na área do lazer, na escola e na saúde pois sua prática tem sido considerada a grande responsável pela melhoria na qualidade de vida das pessoas.

Entende-se desta forma que o esporte pode apresentar-se de outras maneiras e não apenas como produto. Muitos acreditam no esporte como potencializador de socialização entre indivíduos de diferentes classes, religiões, gêneros, entre tantas outras diferenças presentes na nossa sociedade.
Através de uma partida de futebol na rua, de um jogo de vôlei na escola, um jogo de basquete na praça, pessoas se relacionam, fortalecem amizades, criam vínculos mesmo sem nunca terem se visto $^{15}$. Da mesma forma acontece com os eventos esportivos, as pessoas se socializam espontaneamente. É possível perceber o desenvolvimento das relações socioafetivas, a comunicabilidade, a sociabilidade, ajustando o homem ao meio que vive ${ }^{15}$. Seja com o objetivo competitivo, de lazer ou educacional, a socialização com os demais está intimamente ligada ao jogo ${ }^{15}$.

São considerados fatores que influenciam o crescimento da indústria do esporte o aumento do tempo de lazer, o aumento do número e tipos de instalações, eventos e participação, o aumento no número e tipos de atividades esportivas, de fitness e recreativas, bem como o aumento do esporte para a diversidade das populações Pitts, B. G.; Stotlar ${ }^{11}$ E apesar deste cenário que já se apresenta bem consistente percebe-se que o esporte pode ser oferecido não apenas como produto que gera lucros e benefícios direcionados a determinadas classes, mas pode ser oferecido ao interessado em outros segmentos ${ }^{12}$.

Se os eventos são instrumentos do marketing e se o marketing esportivo 
representa uma arma poderosa de promoção não só de uma marca, mas de valores ligados ao esporte, como saúde, vitalidade, juventude, determinação e companheirismo ${ }^{4}$ então, acredita-se que os eventos esportivos podem trazer benefícios as pessoas que se interessam pelo esporte apresentando modalidades e diferentes possibilidades para a prática tanto no lazer, na saúde como na escola.

Sendo assim, percebe-se que os eventos esportivos podem ser uma ferramenta para o incentivo a pratica esportiva em qualquer área inclusive nas escolas. Existe uma grande possibilidade de crescimento do esporte brasileiro não só no alto rendimento, mas de modo geral afinal, o esporte deve estar totalmente vinculado a escola e ao lazer. As diversas possibilidades da prática esportiva devem ser iniciadas na escola dando continuidade fora dela nas atividades de lazer e busca pela vida saudável, podendo ser estendido para o alto rendimento dependendo do interesse pessoal, mas é importante ressaltar que o esporte pode estar presente de diversas formas na vida do indivíduo sendo praticante incentivado por eventos ou pela escola, pelo simples prazer da prática e visando o benefício a saúde.

\section{CONCLUSÃO}

Foi constatado entre os anos de 2008 e 2016 a crescente realização de eventos esportivos no Brasil. A partir do ano de 2010 o número de realizações de eventos esportivos foi crescente e 2014 foi o ano com um maior número de realização computando um total de 1600 eventos em mais de 28 modalidades esportivas dentre elas, atletismo, badminton, basquetebol, boxe, canoagem, ciclismo, esgrima, futebol, ginástica artística, golfe, handebol, hipismo, lutas, natação, pentatlo moderno, polo aquático, remo, rúgbi, saltos ornamentais, taekwondo, tênis, tênis de mesa, tiro esportivo, triatlo, vela, voleibol.

Com o passar dos anos a realização de eventos esportivos apresenta crescimento no Brasil em número de eventos e nas modalidades esportivas e isso pode ser favorável para a sociedade. O marketing esportivo está voltado para grandes eventos e muitas vezes favorece algumas modalidades mais populares. $\mathrm{O}$ esporte brasileiro necessita maiores oportunidades em todas as modalidades esportivas criando possibilidades de maior interação para pessoas de todas as idades.

Espera-se que o crescimento no número de eventos esportivos possa trazer ao esporte, por meio do 
marketing esportivo, maiores possibilidades de interação com a sociedade. Pois, os eventos esportivos podem ser considerados uma ferramenta de fortalecimento e disseminação do esporte no Brasil, independente do seu porte, promovendo momentos de interação entre as pessoas e um maior interesse pela prática desportiva e pela prática do lazer.

\section{REFERÊNCIAS}

1. Morgan MJ, Summers J. Marketing Esportivo. São Paulo: Thomson, 2008

2. Gomes AB. Políticas públicas de incentivo ao esporte universitário e de alto rendimento no Brasil: reflexões e comparações. Dissertação apresentada ao Programa de Pós-graduação em Ciências da Educação, da Universidad del Norte UNINORTE, como requisito parcial para obtenção do grau de Mestre em Educação. Assunção, Paraguai, 2014.

3. Kotler P. e Keller K. Administração de Marketing - 12a Edição. São Paulo: Prentice Hall, 2006.

4. Dualib C. Marketing Esportivo no Brasil. In: STOTLAR, D. K. Como desenvolver planos de marketing esportivo de sucesso. São Paulo: Ideia e Ação, 2005.

5. Pires GMV. Gestão do Desporto: Desenvolvimento Organizacional. APOGESD, 2003.

6. Neto FPM. Marketing Esportivo. Rio de Janeiro: Record, 2003.

7. Zanette, ET. Análise do perfil dos clientes de academias de ginástica: $\mathrm{O}$ primeiro passo para o planejamento estratégico. Dissertação (Mestrado em Engenharia) - Escola de Engenharia, Universidade Federal do Rio Grande do Sul, Porto Alegre, 2003.

8. Kotler P. Marketing de A a Z: 80 conceitos que todo profissional precisa saber. Rio de Janeiro: Campus, 2003. 251 p.

9. Proni M. Marketing e Organização esportiva: Elemento para uma História Recente de EsporteEspetáculo. Campinas, 1998.

10. Pereira GN. A relação entre satisfação e permanência de clientes enquanto consumidores de serviços: um estudo em academias de atividades físicas. Dissertação de mestrado. Brasília: UnB, 2011.

11. Pitts BG; Stotlar DK. Fundamentos de Marketing Esportivo. São Paulo: Phorte, 2002.

12. Pitts BG, Fielding LW, Miller LK. Industry segmentation theory and the sport industry: developing a sport industry segment model. Sport Marketing Quartely (SMQ), 3 (1), 15 - 24, 1994.

13. Projeto Referências. Referências para o esporte de alto rendimento no Brasil. Ministério do esporte Secretaria Nacional de Esporte de Alto rendimento; Universidade Federal do Rio Grande do Sul/Escola de Educação Física/Centro de estudos Olímpicos - 2016. Disponível em: http://referenciasbi.nuvem.ufrgs.br/si te-referencias/ Acesso: outubro/2018.

14. Azevêdo PH. O esporte como negócio: uma visão sobre a Gestão do Esporte nos dias atuais. Estudos, 
v. 36, n. 9/10, p. 929-939, set./out. 2009.

15. Buriti M. Variáveis que influenciam o comportamento agressivo de adolescentes nos esportes. In BURITI, Marcelo de Almeida (Org.). Psicologia do Esporte. Campinas: Editora Alínea, $2^{\mathrm{a}}$ Edição, 2001.

Informações do artigo / Information of this article:

Recebido: 10/01/2019

Aprovado: 17/06/2019

Publicado: 18/11/2019

Received: 10/01/2019

Approved: 17/06/2019

Published: 18/11/2019

Gisele Kede Flor Ocampo

ORCID: 0000-0003-2536-9683.

Contribuição dos autores

Todos os autores participaram do desenvolvimento e execução do estudo, assim como das análises e redação do manuscrito.

\section{Conflito de interesses}

Os autores declaram não haver conflito de interesses.

Como citar este artigo:

OCampo, G. K. F.; Azevedo, A. G.; Ribeiro, A. L. A.; Azevedo, P. H. Os Eventos Esportivos e a Indústria do Esporte no Brasil. Arq. Bras. Ed. Fís., Tocantinópolis, v. 2, n. 1, Jan./Jul., p. 50 - 61, 2019. 